\title{
STUDENTS' PERCEPTIONS OF ASPECTS AFFECTING MEDICAL EDUCATION QUALITY
}

\author{
Katya Peeva, Georgi Arabadzhiev, Georgi Yordanov, Trakia University - Stara Zagora, \\ katya.peeva@gmail.com
}

\begin{abstract}
The student is the main subject in the education process. The goal of the study is to examine the relative weight of the components of learning process in the students' evaluation assessment for quality of higher medical education. Direct individual inquiry with rank answers for 541 medical students was completed. Logistic regression analysis was done to create predictive models and derive relationships between quality of education factors and its dependents: assessment of quality and students' progress. Tolerance and respectfulness $(\mathrm{OR}=13.1)$, high general culture $(\mathrm{OR}=18.4)$, clear and accessible contemporary teaching $(\mathrm{OR}=9.2)$, engagement of the audience $(\mathrm{OR}=3.4)$, are the teacher characteristics in the model. Application of new technologies in learning $(\mathrm{OR}=4.2)$, discussion $(\mathrm{OR}=5.9)$, patients observations and live contact $(\mathrm{OR}=5.6)$ are educational methods determine the quality of education. According interns quality of education is determined mainly by clinical facilities, quality lectures, solving clinical cases, and practical work.
\end{abstract}

UDC numbers: 378, DOI: 10.12955/cbup.2013.44

Key words: students, assessment, quality, education, medicine

\section{Introduction}

Over the years, assessment and evaluation has become a key to the process of improving the quality of education. It is one of the most reliable ways of identifying problems concerning the educational system, a specific school, or an individual student (MAA, 2009). The evaluation of the quality of education is an integral part of the mission of each university. University departments of quality assurance focus on monitoring the quality and strict adherence to assessment systems developed by the university. The purpose of such systems for assessing and maintaining the quality of teaching is to demonstrate the capabilities of the respective university to provide an educational process and a scientific product, so to satisfy the requirements of users and stakeholders.

The cardinal quality principle is focusing on the customer. When we understand internal and external customer needs, we should strive to exceed them (ASQ, 2012). What does 'quality education' mean according to students receiving learning service? How and which elements of education best assess its quality? Quality education is a process that includes learning environment, educational content, processes, outcomes and learner as core elements. The student is the main subject in education process. The attention and efforts of education specialists in general and particularly in medical education are towards the quality of the educational process as a whole and with respect to its results (Kellaghan, 2001). 
An important point is to know the opinions of its users - the students. There is some agreement relating to the reliability and validity of students' evaluation of teaching (Marsh \& Dunkin, 1992). Arguments in support of student ratings of teacher performance and education process by Aleamoni (1984) are: students are the main source of information, the most logical evaluators of the quality, effectiveness, and satisfaction; student ratings encourage communication between them and their instructors and can be used by other students to select courses and instructors.

The goal of students' quality assessment and satisfaction is identification of important medical education elements. By finding these elements will be possible to improve the educational system. To be a quality service, students must assess it as such. This research examines undergraduate medical students' assessment of their education by means of the components of learning process and university teachers' characteristics.

Our analysis shows that research interest in the medical education and its quality in Bulgaria peaked during the years 1980-1987 (Feschieva \& Daskalova, 1980; Ivanov, Feschieva \& Petkova, 1983; Diankov, Feschieva \& Pejchev, 1986). In recent years, surveys designed to assess the quality of medical education were a compulsory part of management in higher medical education in Bulgaria (Kyuchukov, 2009). They are operational in nature, primarily evaluated courses and teachers, but do not recognize the wide range of factors that influence student opinion on medical education (Hadziiliev, 2009). These studies do not aim to reveal characteristic of contemporary medical students and their expectation of education. The growing importance of human resources and lack of research topic ideas in this area in Bulgaria led to this research.

The criteria used in evaluating the activities of higher education institutions today are a wide variety of forms in different countries and universities of the world (Savage, 2005). Diversity largely reflects the different organizational and structural models of higher education systems and the different funding models (Parakh, 2007).

\section{Methods}

A cross-sectional study using individual inquiry with rank answers on a sample of 541 students in three Medical Universities in Bulgaria for the time October 2010 - November 2011 was completed. The respondents were 245 freshmen, 129 third year and 167 interns. Questionnaire was a self-reported structured and had 15 variables for quality assessment of the medical education.

Evaluation of the education factors was using five degree Likert scale - from absolutely agree to absolutely disagree. The data was entered to SPSS and appropriate statistics were computed. The study adopted logistic regression procedures to create predictive models and derive relations between quality of education factors and its dependents: education quality assessment and students' progress. Logistic regression analysis allows estimating the potential effect between the dichotomous variable (education quality assessment and students' progress) and each of the independent variables, no matter what scale are they measured.

The relative risk cross-sectional odds ratio (OR) (odds ratio from a cross-sectional study) is calculated as an assessment. The analysis constructs models which allow calculating the probability of assessing 'quality education' according to the values of a relatively small number of independent variables. The model provides a degree of matching between the views of respondents and the model estimate (predictive power). These models can be used for forecasting. 


\section{Results and Discussions}

Medical students' perceptions for content, forms and effectiveness of undergraduate medical education are a necessary feedback, which can help to manage the educational process. The view of students and receiving feedback from their training is seen as an important resource for evaluating the quality of university medical education and for its improvement. Most of the researches indicate that students and teachers have similar views about what constitutes good teaching (Goldstein \& Benassi, 2006). Some researches into student satisfaction with teaching has shown that students' evaluations depend more on the process activities of teachers than on structural dimensions - students tend to evaluate perceived teaching quality in terms of the characteristics of teachers including their enthusiasm, presentation and clarity (Davies, 2007).

In this study students assess very explicit the teacher's characteristics that determine the quality of education. Accessibility and clarity of teaching, the relevance of curriculum to future professional work, and creating a productive atmosphere are the top three most highly valued teacher characteristics (95\%). More than $90 \%$ of students think that tolerance and respectfulness, using modern technologies in teaching and ability to engage the audience are valuable teacher's characteristics. For the most surveyed students all these characteristics were evaluated as determining high quality of education.

As Richardson et al. $(2005 ; 2007)$ write students place less emphasis on teaching materials, media and facilities such as libraries and computers. In a study from Faculty of Medicine, University of Calgary, aiming to examine students' ratings about their education was made conclusion that implications for teaching have to be focused on improving the organization and delivery of course content that meets the learning objectives (Donnon et al., 2010).

In this study respondents were absolutely agree that observations on clinical practice and live contact with patients are signs of quality education, followed by the possibility of holding discussions with the participation of students and solving cases during the workshops (more than 90\%). There was obviously a positive attitude towards active learning methods, even for freshmen who still lack experience but have the idea that this would increase their level of training. Using video and movies for lectures, multimedia opportunities, emphasis on interconnection of different subjects, and supplementing the textbook were positively valued by more than $3 / 4$ of students.

Over the years of education high assessment of routine methods has reduced and the importance of student-patient contact and the ability for independent work on assigned problem has increased. The importance of expanding and complementing the materials from the workbooks was increased. Student services, such as scholarships, library and Internet access were defined as mandatory for high quality education from about $90 \%$ of surveyed.

\section{Teacher characteristics and educational methods}

The logistic regression analysis identified teacher characteristics that influence education quality assessment with odds ratio $(\mathrm{OR})$ : high general culture $(\mathrm{OR}=18.41)$, tolerance and respectfulness $(\mathrm{OR}=13.12)$, contemporary teaching $(\mathrm{OR}=9.3)$, clear and accessible teaching $(\mathrm{OR}=5.7)$, to be demanding $(\mathrm{OR}=2.73$ ) (Figure 1$)$. Overall predictive power of this model was $73.5 \%$. Discussion $(\mathrm{OR}=5.97)$, patients observations and live contact $(\mathrm{OR}=5.61)$, and application of new technologies 
in learning ( $\mathrm{OR}=4.15)$ were educational methods in the logistic regression model that determine the quality of education (Figure 2). Overall predictive power of the model was $61.3 \%$.

Figure 1: Teacher's characteristics determining quality of education (with OR and 95\% Confidence Interval)

$\mid \begin{aligned} & 150 \\ & 100\end{aligned}$

Source: Author

Figure 2: Educational methods determining quality of education (with OR and 95\% Confidence Interval)

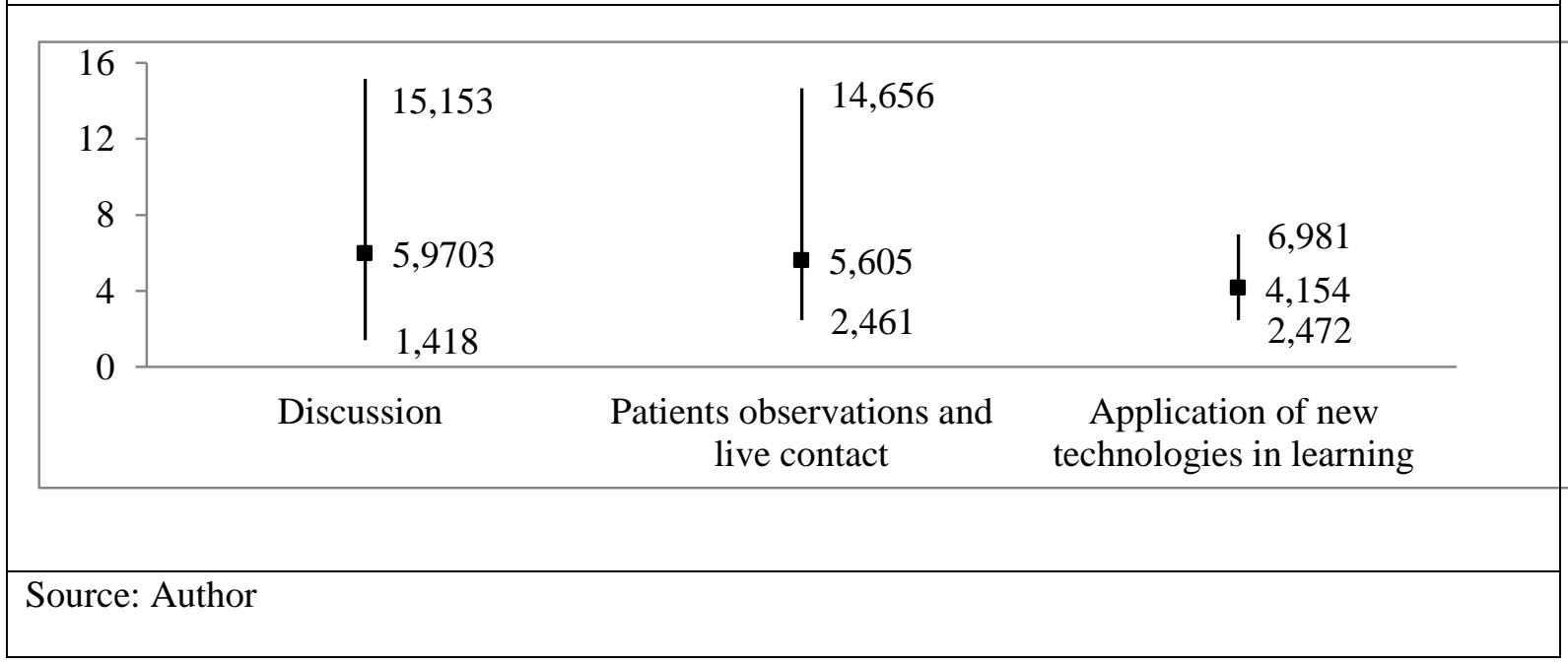

According interns overall quality of education is determined mainly by clinical facilities, quality lectures, solving clinical cases, and practical work.

\section{Quality assessment and students' progress}

Multivariate regression analysis techniques were used to identify the relation between the independent variables and education quality assessment. Regression analysis revealed that four variables had the most effect on assessing education as quality one - teacher's tolerance and respectfulness ( $O R=5.98)$, students' assessment of teachers $(\mathrm{OR}=4.15)$, using videos and movies $(\mathrm{OR}=2.7)$, and final written 
exam (OR $=2.25)$ as a form of knowledge evaluation that define high quality education (Table 1$)$. Overall predictive power of this model was $76.2 \%$.

Table 1: Model for assessment of education quality (with OR and 95\% Confidence Interval)

\begin{tabular}{|l|c|c|c|c|c|c|c|c|}
\hline $\begin{array}{l}\text { Variables in the } \\
\text { Equation }\end{array}$ & B & SE & Wald & df & Sig. & $\begin{array}{c}\text { Exp (B), } \\
\text { OR }\end{array}$ & \multicolumn{2}{|c|}{$\begin{array}{c}\text { EX\% CI for } \\
\text { EXP (B) }\end{array}$} \\
\hline $\begin{array}{l}\text { Tolerance and } \\
\text { respectfulness }\end{array}$ & 1.789 & 1.264 & 2.004 & 1 & 0.157 & 5.982 & 1.503 & 17.207 \\
\hline $\begin{array}{l}\text { Students' assessment of } \\
\text { teachers }\end{array}$ & 1.424 & 0.265 & 28.909 & 1 & 0.000 & 4.154 & 2.472 & 6.981 \\
\hline $\begin{array}{l}\text { Using videos and } \\
\text { movies }\end{array}$ & 0.994 & 0.329 & 9.121 & 1 & 0.003 & 2.703 & 1.418 & 5.153 \\
\hline Final written exam & 0.810 & 0.264 & 9.453 & 1 & 0.002 & 2.249 & 1.342 & 3.770 \\
\hline
\end{tabular}

Source: Author

Multiple regression analysis revealed that students' progress depends mostly on teacher's ability to make a creative atmosphere, stimulate independent thinking $(\mathrm{OR}=3.07)$ and engage the audience (OR $=2.88)$. Using contemporary technologies $(\mathrm{OR}=2.15)$ that draw students' attention make difference in their final evaluation as well as current control during the term $(\mathrm{OR}=1.74)$ (Table 2). Overall predictive power of the model was $56.2 \%$.

Table 2: Model for students` progress (with OR and 95\% Confidence Interval)

\begin{tabular}{|l|c|c|c|c|c|c|c|c|}
\hline Variables in the Equation & B & SE & Wald & df & Sig. & $\begin{array}{c}\text { Exp } \\
\text { (B), OR }\end{array}$ & \multicolumn{2}{|c|}{$\begin{array}{c}\text { EX\% CI for } \\
\text { EXP (B) }\end{array}$} \\
\hline $\begin{array}{l}\text { To make a creative atmosphere } \\
\text { and stimulate independent } \\
\text { thinking }\end{array}$ & 1.122 & 0.422 & 7.070 & 1 & 0.008 & 3.071 & 1.343 & 7.023 \\
\hline To be able to engage the audience & 1.059 & 0.331 & $\begin{array}{c}10.22 \\
8\end{array}$ & 1 & 0.001 & 2.885 & 1.507 & 5.521 \\
\hline Using videos and movies & 0.766 & 0.259 & 8.725 & 1 & 0.003 & 2.151 & 1.294 & 3.576 \\
\hline Current control during the term & 0.552 & 0.243 & 5.171 & 1 & 0.023 & 1.737 & 1.079 & 2.796 \\
\hline
\end{tabular}

Source: Author

\section{Conclusion}

Accessibility and clarity of teaching, high general culture, tolerance and respectfulness, contemporary teaching, and be required are the most highly valued teacher's characteristics. High education quality assessment is defined by teacher's tolerance and respectfulness, use of contemporary 
technologies, students' assessment of teachers, and final written exam. Students' progress depends mostly on teacher's ability to make a creative atmosphere, stimulate independent thinking, and engage the audience, use of contemporary teaching methods, and current control during the term.

The study defines essential characteristics that have a predictive value for future evaluation and practical significance to identify the students' expectations of quality medical education. It provides theoretical and practical implications to guide the design of teaching assessment. Design and experimental verification of the criteria and methodology for the process of assessing the quality of education at Medical Universities is done. Students identify the need for strong positive role models in their learning environment, and for effective evaluation of the professionalism of teachers.

Using recognized and objective criteria and evaluation systems, institutions will be able to make reasonable justification in defense of the higher medical education as a public service and promote it as a crucial sector of society in a time of a global knowledge economy. Objective criteria of assessing the quality of medical education are vital for its successful management and improvement.

\section{References}

Aleamoni, L. M. (1984). Student ratings of instruction. In J. Millman (Ed.). Handbook Of Teacher Evaluation. Beverly Hills, CA: SAGE Publications.

ASQ, World Quality Month. (2012, November). The cost of poor quality. Retrieved November 9, 2012, from http://asq.org/world-quality-month/index.aspx

Davies, M., Hirschberg, J., Lye, L., Johnston, C. \& McDonald, I. (2007). Systematic influences on teaching evaluations: the case for caution. Australian Economic Papers, 3, 18-38.

http://dx.doi.org/10.1111/j.1467-8454.2007.00303.x

Djankov, E., Feschieva, N. \& Peychev, N. (1986). Sotsiologicheski izsledvaniya i upravlenie na uchebno-vuzpitatelniya protses vuv VMI [Sociological research and management of the educational process at VMI]. Paper presented at Second creative meeting-competition "Inventions and, best practices in healthcare region of Varna" held in Varna, Bulgaria.

Donnon, T., Delver, H. \& Beran, T. (2010). Student and teaching characteristics related to ratings of instruction in medical sciences graduate programs. Medical Teacher, Vol. 32, No. 4, 327-332. http://dx.doi.org/10.3109/01421590903480097 PMid:20353330

Feschieva, N. \& Daskalova, S. (1980). Uchebno vŭzpitatelen protses - faktor za profesionalnata adaptatsiya na studentite-meditsi. Rezultati ot edna anketa [Academic educational process - a factor for occupational adaptation of medical students. Results of a survey]. Medical science and education, $5,3-5$.

Goldstein, G. S. \& Benassi, V. A. (2006). Students' and instructors' beliefs about excellent lecturers and discussion leaders. Research in Higher Education, 47(6), 685-707.

http://dx.doi.org/10.1007/s11162-006-9011-x

Hadziiliev, V. (2009). Analiz na studentskoto mnenie za vŭvezhdaneto na novi formi v obuchenieto po khimiya v Meditsinski fakultet, TU, Stara Zagora [Analysis of the students' opinion on the introduction of new forms of teaching chemistry at the Medical Faculty, Trakia University, Stara 
Zagora]. Proceedings of Second National Conference with international participation "The quality of higher education in Bulgaria - problems and prospects" held in Rousse, Bulgaria, Vol. 1, p. 191-201.

Ivanov, K., Feschieva, N. \& Petkova, L. (1983). Aktivnoto obuchenie - sredstvo za povishavane efektivnostta na uchebniya protses po sotsialna khigiena i organizatsiya na zdraveopazvaneto [Active learning - a tool for increasing the efficiency of learning in social hygiene and health care organization]. Paper presented at Jubilee Session Medical Faculty, Tolbuhin and High Institute of Medicine, Varna, held in Tolbuhin, Bulgaria, October 29, 1983.

Kellaghan, T. \& Greaney, V. (2001). Using assessment to improve the quality of education. UNESCO: International Institute for Educational Planning. Retrieved December 11, 2009 from http://www.unesco.org/iiep

Kyuchukov, R. (2009). Anketiraneto kato element na sistemite po kachestvo vuv visshite uchilishta [Interview as part of quality systems in higher education]. Paper presented at Second National Conference with international participation "The quality of higher education in Bulgaria - problems and prospects" held in Rousse, Bulgaria.

Marsh, H. W. \& Dunkin, M. J. (1992). Students' evaluations of university teaching: A multidimensional perspective. In J. C. Smart (Ed.). Higher education: Handbook of theory and research, Volume 8. New York, NY: Agathon Press.

Mathematical Association of America. (2009). What is assessment? Retrieved December 11, 2009, from http://www.maa.org/SAUM/faq.html

Parakh, K. (2007). Assessment in Medical Education. N Engl J Med, 356, 2108-2110, http://dx.doi.org/10.1056/NEJMc070466

Richardson, J. T. E. (2005). Instruments for obtaining student feedback: A review of the literature. Assessment and Evaluation in Higher Education, 30(4), 387-415. http://dx.doi.org/10.1080/02602930500099193

Richardson, J. T. E., Slater, J. B. et al. (2007).The National Student Survey: Development, findings and implications. Studies in Higher Education, 32(5), 557-580.

http://dx.doi.org/10.1080/03075070701573757

Savage, C. S., Uhre, K., Kova, V., Wennekes \& Jensen-Dahm, C. (July 6-10, 2005). Quality assurance in medical schools. Copenhagen, Denmark: Department of Learning, Informatics, Management and Ethics (LIME). 